
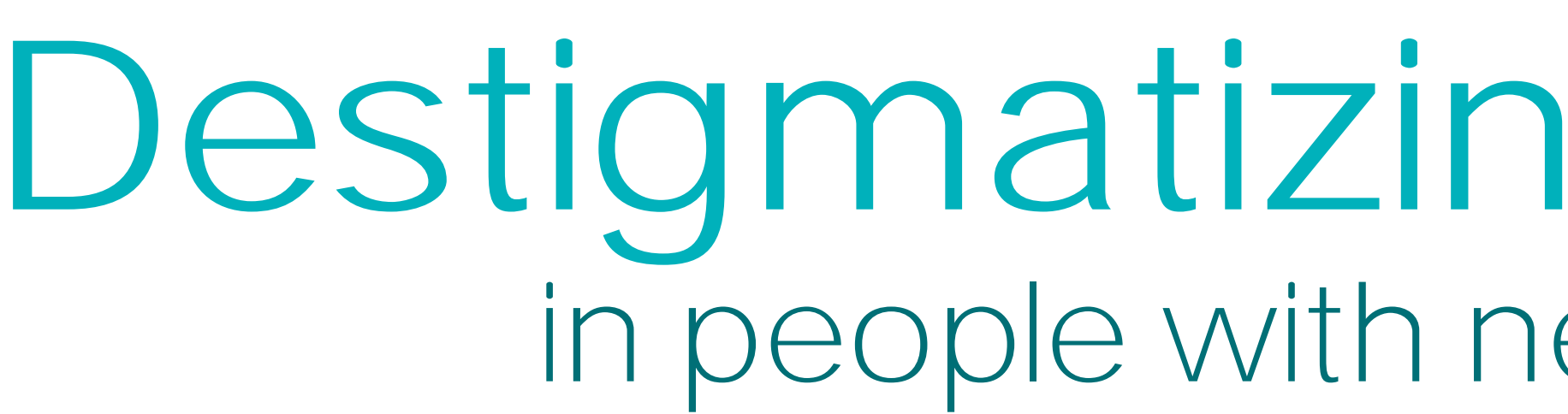

\title{
Diana Princess
}

\author{
of Wales was \\ known for her \\ ability to ignore \\ stigma
}

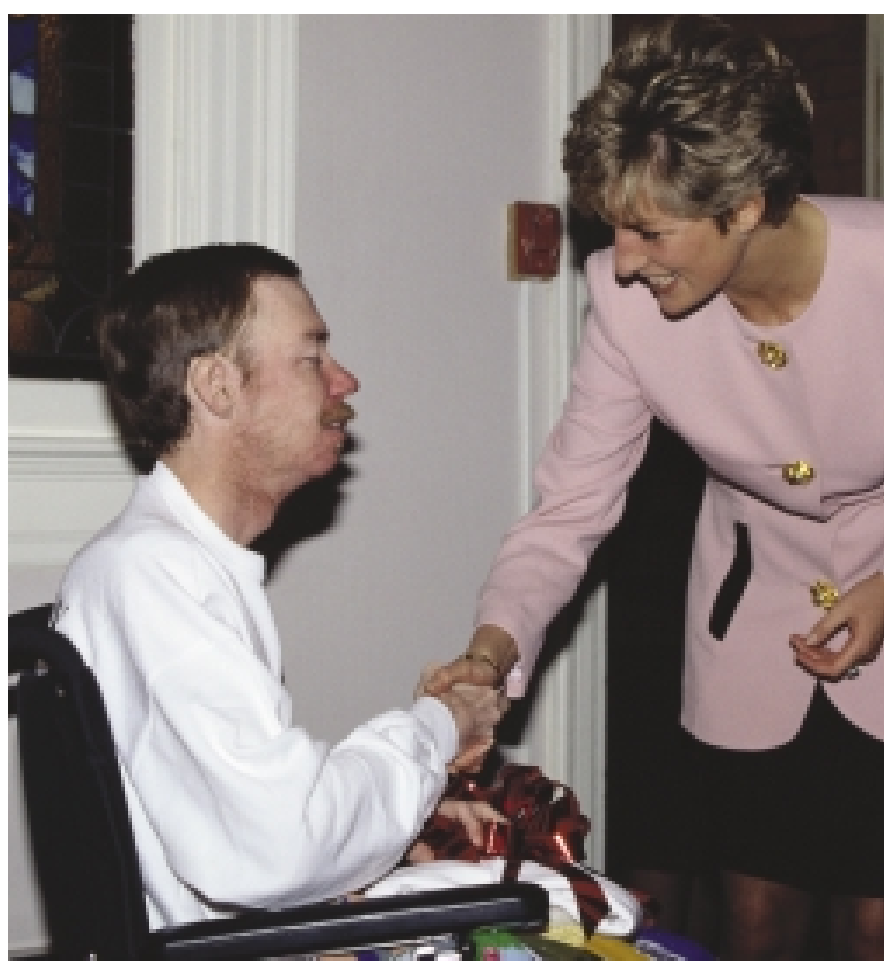

For educated and intellectually curious adults who arewithout specialist or scientific training, it would be difficult for neurologists to exaggerate the value of articles in medical journals. I hear repeatedly from patients - and their families - with various neurological problems how helpful it is to read the medical literature. On the other hand, it would be easy for neurologists to misinterpret their motivation. It is incorrect to think that the patient's search represents a single-minded inquiry just for more scientific knowledge - the facts - explaining the biological basis of a neurological disorder, and its treatment. To be sure, this information is no less important for patients than for their doctors, but the patient's quest is also for a greater understanding of the meaning of illness and its impact on their quality of life. It is therefore essential that even primarily 'medical' journals encompass thebroad scope of difficul- ties encountered by patients and the full range of services that may be required. This is really a question of thedistinction between thedoctor's perspective and the patient's perspective, the onefocused on diseaseand theother centred on illness. Or, if you will, a need to identify the twin domains of neurobiology and suffering.

In myown reading, for example, I am especially keen on articles written by doctors who have themselves become patients, a role transformation that is often described by the authors as an epiphany of sorts. It is good therefore to seethat Practical Neurology runs articles written by neurologists about their own neurological illnesses. Thereisan overarching themethat runsthrough such articles, namely a sudden awareness that the author's undergraduate and postgraduate medical education has turned out to be a woefully inadequate preparation for the experience of actually being a patient. After years of clinical 
experience, medically qualified authors seem bewildered that medical care can be such a dehumanizing experience, or that medical illness is so often a cause of traumatic social dislocation that may result in depression and anger.

The problem of stigma and neurological illness emerge together. Patients live with stigma constantly, yet their doctors are largely unaware of thisintenseburden. Indeed, someneurologists believe that stigma is only a problem for people with psychiatric problems, and is relatively unimportant for patients with clearly biological disorders affecting the nervous system. Thus the neurological literatureislargely silent on stigma. I haverepeatedly attempted to enlist thesupport of the global organizations of neurologists to examinethe problem of stigma for neurological patients, and what can be done about it. What I have encountered is often a disturbing mix of disbelief and disinterest. Because most patients with neurological disorders have clearly identifiable symptoms does not mean that they are thereby free of the stigma that attaches to so-called mental illnesses. This is not to say that peoplewith problemssuch asschizophreniaand bipolar disorder are not subjected to an unacceptable degree of stigma and discrimination, or that their unnecessary suffering is not greater than people with other brain disorders. On the contrary, we should all agree with Sartorius that such stigma is to somedegreea response, related to the attitudes and behaviour of psychiatrists and other doctors (Sartorius 2002).

My colleagues and I have argued that advancesin neuroscienceresearch havenow made it impossible to draw a clear line between neurological and psychiatric disorders, and have rendered theconcept of mental illnessmeaningless (Baker \& M enken 2001; Baker et al. 2002). This applies to the psychological and social dimensions of brain illness no less than those dimensions that are solely neurobiological. The 20th century schism between neurology and psychiatry makes no sense from the patient's perspective, and efforts to heal it should be applauded. It is surely important for neurologists and all doctorsto understand that, if it takestwo to tango, then it al so takestwo or morepeopleto createstigma, which is a social phenomenon.

Stigma arises from the human quest for perfection and the avoidance of that which is flawed, from a sense of being different, from the guilt of being a burden or an obstacle that creates a hardship for others. Without appropriate education, children spontaneously stigmatize and discriminatetheir peers who are unusual in someway, and accept without question theneed to conform by displaying physical traits and behaviours that are accepted and characteristic of a social group. Spinoza got it just right when he wrote, 'I do not attributeto natureeither beauty or deformity, order or confusion. Only in relation to our imagination can things be called beautiful or ugly, well-ordered or confused' (quoted in Durant 1933).

Recently, I accepted the challenge to work as an editor of the British M edical Journal so I could present the patients' and families' viewpoints, concerns, needs, and interests pertaining to neurological (and other) disorders - for professionals, health ministries, and the general public. I hope that the universe of neurologists and other doctors, and their professional organizations, will join me in this effort. The public interest demands no less.

\section{REFERENCES}

Baker M G, KaleR \& M enken M (2002) Thewall between neurology and psychiatry. BM J , 324, 1468-9.

Baker M \& M enken M (2001) Timeto abandon theterm mental illness. BM J, 322, 937-8.

Durant W (1933) Thestory of philosophy, p. 133. Simon and Schuster, N ew York

Sartorius N (2002) Iatrogenic stigma of mental illness. BMJ, 324, 1470-1.

\section{"I do not attribute}

to nature either beauty or deformity, order or confusion. Only in relation to our imagination can things be called beautiful or ugly, wellordered or confused"

Baruch Spinoza 